\title{
Psychotic features in patients with Bipolar I Mood Disorder current episode mania
}

\author{
Aditi Dagaonkar ${ }^{1}$, Bindoo Jadhav ${ }^{2}$, Bharat Shah ${ }^{3}$, Hemangee S. Dhavale ${ }^{4}$, Sumita Shanker ${ }^{5}$ \\ ${ }^{1}$ Registrar \\ ${ }^{2}$ Professor \\ ${ }^{3}$ Professor and Head \\ ${ }^{4}$ Hon. Professor \\ ${ }^{5}$ Clinical Psychologist \\ Department of Psychiatry, K.J. Somaiya Medical College, Hospital and Research Centre, Sion, Mumbai. \\ E-mail - aditidagaonkar@gmail.com
}

\begin{abstract}
Background: Psychosis is quite common in Bipolar Disorder, with approximately half of the patients possessing a lifetime history of psychotic symptoms during a mood episode. Yet there has been little focus on psychotic mania as a meaningful subtype. The aims and objectives of the current research were to study the prevalence of psychotic features in patients with Bipolar I Mood Disorder in Mania, to study the sociodemographic and illness related variables of patients with psychotic features in Bipolar I Mood Disorder in Mania and to compare the patients of Bipolar I Mood Disorders in Mania with and without psychotic features.

Methods: 50 consecutive patients diagnosed as having Bipolar I Mood Disorder currently in mania were selected. The patients were clinically assessed for delusions and hallucinations and their scores on the Young Mania Rating Scale (YMRS) and Brief Psychiatric Rating Scale (BPRS) were noted. They were then divided into two groups viz. with and without psychotic features and compared on sociodemographic and illness related variables.

Results: $58 \%$ of the patients showed the presence of psychotic features, with grandiose delusions being the most common type of psychotic symptoms. Patients with psychotic features had significantly higher scores on the YMRS and BPRS.

Discussion: Our findings are in keeping with earlier research which also shows that psychotic symptoms tend to occur in severe mania.

Conclusion: Psychotic symptoms are common in mania and need to be evaluated.
\end{abstract}

Key words: Bipolar I Mood Disorder, mania, delusions, hallucinations, mood congruence, manic.

(Article received $-29^{\text {th }}$ April 2016, Peer Review completed $-1^{\text {st }}$ June 2016, Accepted $-13^{\text {th }}$ June 2016)

\section{INTRODUCTION}

Bipolar Mood Disorder remains a severe and recurrent mental illness for most patients despite advances in pharmacological treatments. Over $70 \%$ of patients relapse within five years of an index episode [1] and approximately half of those who do not relapse continue to experience impairing sub-threshold mood symptoms [2-3].

Researchers have attempted to identify features of the bipolar illness that may be predictive of its severity and course, including the presence of psychotic symptoms during mood episodes. Psychosis is quite common in bipolar disorder, with approximately $58 \%$ of the patients possessing a lifetime history of psychotic symptoms during a mood episode [4]. Grandiose delusions are the most common type of 
psychotic symptom, but any kind of psychotic symptom, including thought disorder, hallucinations, mood incongruent psychotic symptoms and catatonia can present as a part of the mood episode [5]. However, even though psychosis is regarded as a prominent characteristic of a manic episode, it is not really clear whether psychosis is a dimensional aspect of severe psychiatric illness that is superimposed on other aspects of manic episode, or psychotic features are an integral part of the severe manic syndrome. Similar contradictory opinions exist as regards to the impact psychotic symptoms have on the course of bipolar mood disorder.

In their classic paper, Pope and Lipinski [6] argued that psychosis associated with severe affective illness is relatively common and not of prognostic significance. Different researchers have reported a variety of conflicting results. Some studies have concluded that psychotic symptoms are predictive of worse psychosocial outcome [7-8] whereas others [9-10] have found no relationship whatsoever between psychosis and any long term outcomes.

As psychotic features are relatively common in manic states and their association with disease outcome is not conclusively established, there has been little focus on psychotic mania as a meaningful subtype. The phenomenological and prognostic significance of psychotic features for depressive syndromes [11-12] however warrants analysis to determine whether psychotic features may be similarly predictive for mania as they are in depression.

This study was therefore undertaken to study the prevalence of psychotic features in patients with Bipolar I Mood Disorder in mania, to study the socio-demographic and illness related variables of patients with psychotic features in Bipolar I Mood Disorder in mania and to compare the patients of Bipolar I Mood Disorders in Mania with and without psychotic features.

\section{METHODOLOGY}

\section{Materials:}

1. Diagnostic and Statistical Manual IV Text Revision. (DSM IV TR) [13] was used in the diagnosis of mania.

2. Semi-structured proforma: This was specially designed for the study to obtain various sociodemographic and illness related variables.

3. Modified Kuppuswamy scale (Urban) (2001) [14]: This scale was used to measure the socioeconomic status of the patient. This scale has been widely used in clinical research and is specially designed for use in urban areas where this study was conducted.

4. Global Assessment of functioning scale (GAF) [15]: This scale is a commonly used scale in clinical practice for reporting the clinician's judgment of the individuals overall level of functioning. Functioning is considered a composite of three major areas: social functioning, occupational functioning and psychological functioning. It is based on a continuum of mental health and mental illness.

5. Young Mania Rating Scale (YMRS) [16]: It was developed by Young and others and is one of the most frequently used scales to assess manic symptoms. Inter-rater reliability is reported to be 0.93 .

6. Brief Psychiatric Rating Scale (BPRS)[17]: This scale was developed by Overall and Gorham. It is widely used for evaluating major psychotic and non-psychotic symptoms in individuals with a major psychiatric disorder. Reliability co-efficient of 0.56 to 0.87 have been reported.

\section{Inclusion Criteria for patients in the study:}

1. Patients fulfilling DSM IV TR diagnostic criteria for Bipolar I Mood Disorder at present in Mania

2. Patients with age between 18 to 50 years.

3. Patients and relatives consenting to be enrolled in the study.

\section{Exclusion Criteria:}

1. Patients with Bipolar I Mood Disorder, currently depressed or in mixed states.

2. Patients with diagnostic dilemma, substance dependence or any other psychiatric morbidity.

3. Patients with mental retardation, dementia or any history suggestive of organic disorders. 
4. Patients with medical co-morbidities, pregnancy and within 6 months post partum.

\section{Study outline:}

1. Approval of the Ethics Committee was taken prior to commencing the study.

2. Patients and their relatives were informed of the research objectives and assured of the confidentiality of their responses. Informed consent was taken.

3. Consecutive patients diagnosed as having Bipolar I Mood Disorder in Mania as per DSM IV TR ${ }^{13}$ and fulfilling inclusion/exclusion criteria were selected.

4. The various socio-demographic and illness related variables were recorded using the specially designed semi-structured proforma.

5. The Modified Kuppuswamy scale (Urban) ${ }^{14}$ was used to measure the socio-economic status of the patient.

6. The patients were clinically assessed for the presence of psychotic features according to DSM IV TR i.e. delusions and hallucinations. The content of the delusions and hallucinations was noted, and the patients were grouped according to the DSM IV TR [13] classification of mood congruent or mood incongruent.

7. The Young Mania rating scale (YMRS) [15] was used to assess the severity of Mania.

8. The Brief Psychiatric Rating Scale (BPRS) [16] was used to evaluate the psychotic symptoms in patients.

9. The patient's level of functioning was rated using the Global Assessment of functioning (GAF) [17] scale.

10. The data that was thus obtained was pooled and divided into two groups:

a. Patients with psychotic features

b. Patients without psychotic features

11. The two groups were then compared and any difference between the two groups was noted. The following parameters were studied
a. Socio-demographic variables
b. Age of onset of illness (Adolescent versus Adult)
c. Presence or absence of family history of mental illness
d. Co-morbid substance use
e. The scores on the YMRS
f. The scores on the BPRS
g. The scores on the GAF scale.

\section{STATISTICAL ANALYSIS}

The entire data was analyzed using the SPSS statistical software and the results were presented.

\section{RESULTS}

A total of 50 patients with Bipolar I Mood Disorder at present in Mania were studied. Of these, 29 were males and 21 were females.

\section{Prevalence of psychotic features in patients with Bipolar I Mood Disorder in Mania:}

Psychotic features were defined as the occurrence of delusions and hallucinations.

Of the 50 patients studied, 29 patients i.e. $58 \%$ were found to have psychotic features, as seen in Figure 1.

Of the 29 male patients, $16(55.2 \%)$ had psychotic features, while out of the 21 females, $13(61.9 \%)$ had psychotic features. Thus, the prevalence of psychotic features was more in females.

\section{Types of psychotic features:}

Of the 29 patients who had psychotic features, 19 i.e. $66 \%$ had mood congruent psychotic features, while 10 i.e. $34 \%$ had mood incongruent psychotic features.

Types of delusions and hallucinations:

All of the 29 patients with psychotic features had one or more type of delusion. 
Of these, 15 patients (51.7\%) had only delusions and 6 patients had a single type of delusion while 23 patients had more than one type of delusion.

In this study, 14 patients (48.3\%) had hallucinations along with delusions. None of the patients had hallucinations in the absence of delusions. $54 \%$ had grandiose delusions while $46 \%$ had delusions of reference and another $46 \%$ had delusions of persecution. Delusions of control were seen in $8 \%$ subjects and somatic delusions were seen in $4 \%$ cases.

All these 14 patients had only auditory hallucinations. None of the patients had visual hallucinations or hallucinations in any other modality.

Socio-demographic profile of patients with psychotic features in Bipolar I Mood Disorder in Mania: The socio-demographic variables of all patients are discussed in Table 1

Table 1: The socio-demographic profile of patients with psychotic features in Bipolar I Mood Disorder in Mania

\begin{tabular}{|c|c|}
\hline Domain & No. of patients $(n=29)$ \\
\hline Mean Age & 31.72 years \pm 10.30 years \\
\hline $18-30$ years & $19(65.5 \%)$ \\
\hline $31-50$ years & $10(34.5 \%)$ \\
\hline \multicolumn{2}{|l|}{ Sex } \\
\hline Males & $16(55.2 \%)$ \\
\hline Females & $13(44.8 \%)$ \\
\hline \multicolumn{2}{|l|}{ Education } \\
\hline Illiterate & $3(10.3 \%)$ \\
\hline Primary & $5(17.2 \%)$ \\
\hline Secondary & $10(34.5 \%)$ \\
\hline S.S.C. & $3(10.3 \%)$ \\
\hline H.S.C. & $2(6.9 \%)$ \\
\hline Graduate & $6(20.7 \%)$ \\
\hline Post Graduate & 0 \\
\hline \multicolumn{2}{|l|}{ Occupation } \\
\hline Unemployed & $11(38 \%)$ \\
\hline Housewife & $5(17.2 \%)$ \\
\hline Service & $13(44.8 \%)$ \\
\hline Self Employed & $3(10.3 \%)$ \\
\hline Students & $3(10.3 \%)$ \\
\hline \multicolumn{2}{|l|}{ Marital Status } \\
\hline Unmarried & $13(44.9 \%)$ \\
\hline Married & $12(41.4 \%)$ \\
\hline Separated or Divorced & $4(13.8 \%)$ \\
\hline Widowed & 0 \\
\hline \multicolumn{2}{|l|}{ Socio-Economic Status } \\
\hline Lower & $1(3.44 \%)$ \\
\hline Upper Lower & $16(55.1 \%)$ \\
\hline Lower Middle & $10(34.4 \%)$ \\
\hline Upper Middle & $2(6.89 \%)$ \\
\hline Upper & 0 \\
\hline
\end{tabular}

The illness related variables of patients with psychotic features in Bipolar I Mood Disorder in Mania:

a. Age at onset: Of the 29 patients with psychotic features, 10 (34.5\%) of the patients had an adolescent age of onset while $19(65.5 \%)$ of the patients had and adult age of onset. 
b. Family History: A positive family history of mental illness was present in $12(41.4 \%)$ patients with psychotic features. Among these, a family history of mood disorder could be reliably ascertained in $7(58.3 \%)$ of the patients, while a family history suggestive of schizophrenia was noted in 2 $(16.6 \%)$ of the patients.

c. Also, $2(16.6 \%)$ of the patients reported a family history of some mental illness but could not give accurate information about the nature of the mental illness neither were they able to produce any medical records and hence the exact diagnosis could not be confirmed.

d. History of Substance Use: In our study, 16 (55.2\%) patients had a positive history of substance abuse. Of these, 12 were males and 4 were females. Nicotine use was seen in 10 cases while 6 cases showed alcohol and 3 cases showed both alcohol and nicotine use.

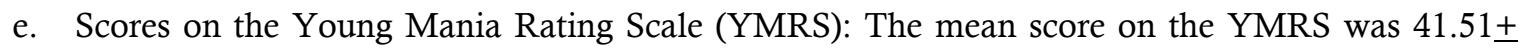
8.05 .

- $4(13.8 \%)$ patients had a score between $20-30$

- $6(20.7 \%)$ patients had a score between 31- 40

- $19(65.5 \%)$ patients had a score of 41 and above

f. Scores on the Brief Psychiatric Rating Scale (BPRS): The mean score on the BPRS was $46.31 \pm$ 7.20

g. Scores on The Global Assessment of Functioning (GAF) Scale: None of the patients had a GAF score higher than 41-50. (Table 3)

Table 2: Scores on the GAF Scale

\begin{tabular}{|cc|}
\hline Score on the GAF Scale & Percentage of patients \\
\hline $11-20$ & $14 \%$ \\
\hline $21-30$ & $49 \%$ \\
\hline $31-40$ & $34 \%$ \\
\hline $41-50$ & $3 \%$ \\
\hline
\end{tabular}

Comparison of the two groups of patients i.e. patients with Bipolar I Mood Disorder in Mania with and without psychotic features:

The socio-demographic profile of both groups was compared using the chi square test and the results are as shown in Table 3.

There was a significant difference in the socio-economic status between the two groups with the psychotic symptoms group faring poorly on the Kuppuswamy scale. There was no significant difference between the two groups on any other parameter in the socio-demographic profile.

The illness related variables between the two groups were compared using the t test and the results are as shown in Table 4. As seen from the table below, the patients with psychotic features had significantly higher scores on the YMRS and the BPRS as compared to the patients without psychotic features. The two groups did not differ significantly on any other illness related parameters.

\section{DISCUSSION}

A total of 50 patients with Bipolar I Mood Disorder at present in Mania were studied. Of these, 29 were males and 21 were females. In this study, 29 patients i.e. $58 \%$ of the patients were found to have psychotic symptoms i.e. delusions and hallucinations. Goodwin and Jamison [4] also found a prevalence of psychotic features to be $58 \%$ in Bipolar I Mood Disorder. Other studies done in the past [18-19] have also found rates similar to the present study. However, one study has reported a much higher incidence of $80 \%$ [20], while another study [21] has reported much lower rates of $42.6 \%$. There could be few reasons for this discrepancy. The present study used a narrow definition of psychosis. Formal thought disorder and disorganized behavior were not included even though they are often considered psychotic. Analysis of the structure of psychosis has suggested that delusions and hallucinations may be independent of thought disorder and disorganization. 
Table 3: Comparison of the two groups on the socio-demographic profile

\begin{tabular}{|c|c|c|c|}
\hline Domain & $\begin{array}{l}\text { With psychotic features } \\
\qquad(n=29)\end{array}$ & $\begin{array}{l}\text { Without psychotic } \\
\text { features } \\
(n=21)\end{array}$ & $\begin{array}{l}\text { Statistics } \\
\text { (p value) }\end{array}$ \\
\hline $\begin{array}{c}\text { Age } \\
18-30 \text { years } \\
31-50 \text { years }\end{array}$ & $\begin{array}{l}19(65.5 \%) \\
10(34.5 \%)\end{array}$ & $\begin{array}{l}11(52.3 \%) \\
10(47.7 \%)\end{array}$ & $0.349 \mathrm{NS}$ \\
\hline $\begin{array}{c}\text { Sex } \\
\text { Males } \\
\text { Females }\end{array}$ & $\begin{array}{l}16(55.2 \%) \\
13(44.8 \%)\end{array}$ & $\begin{array}{l}13(61.9 \%) \\
8(38.1 \%)\end{array}$ & $0.634 \mathrm{NS}$ \\
\hline $\begin{array}{l}\text { Education } \\
\text { Illiterate } \\
\text { Primary } \\
\text { Secondary } \\
\text { SSC } \\
\text { HSC } \\
\text { Graduate }\end{array}$ & $\begin{array}{c}3(10.3 \%) \\
5(17.2 \%) \\
10(34.5 \%) \\
3(10.3 \%) \\
2(6.9 \%) \\
6(20.7 \%)\end{array}$ & $\begin{array}{c}1(4.76 \%) \\
4(19.04 \%) \\
9(42.9 \%) \\
4(19.04 \%) \\
0 \\
3(14.3 \%)\end{array}$ & $0.684 \mathrm{NS}$ \\
\hline $\begin{array}{c}\text { Marital Status } \\
\text { Unmarried } \\
\text { Married } \\
\text { Separated or Divorced }\end{array}$ & $\begin{array}{c}13(44.9 \%) \\
12(41.4 \%) \\
4(13.8 \%)\end{array}$ & $\begin{array}{c}10(47.7 \%) \\
11(52.3 \%) \\
0\end{array}$ & $0.198 \mathrm{NS}$ \\
\hline $\begin{array}{c}\text { Socio-Economic Status } \\
\text { Lower } \\
\text { Upper Lower } \\
\text { Lower Middle } \\
\text { Upper Middle }\end{array}$ & $\begin{array}{c}1(3.44 \%) \\
16(55.1 \%) \\
10(34.4 \%) \\
2(6.89 \%)\end{array}$ & $\begin{array}{c}3(14.3 \%) \\
5(23.8 \%) \\
3(14.3 \%) \\
10(47.7 \%)\end{array}$ & $0.002^{*}$ \\
\hline
\end{tabular}

(* significant, $\mathrm{p}<0.05),(\mathrm{NS}-$ not significant) (Chi square test used)

Table 4: Comparison of the two groups on the illness related variables

\begin{tabular}{|c|c|c|c|}
\hline Domain & $\begin{array}{l}\text { With psychotic features } \\
\qquad(n=29)\end{array}$ & $\begin{array}{l}\text { Without psychotic features } \\
\qquad(n=21)\end{array}$ & p value \\
\hline $\begin{array}{c}\text { Age of onset } \\
\text { Adolescent } \\
\text { Adult }\end{array}$ & $\begin{array}{l}10(34.5 \%) \\
19(65.5 \%)\end{array}$ & $\begin{array}{l}7(33.33 \%) \\
14(66.66 \%)\end{array}$ & $0.933 \mathrm{NS}^{\mathrm{a}}$ \\
\hline $\begin{array}{c}\text { Positive family history } \\
\text { Present } \\
\text { Absent }\end{array}$ & $\begin{array}{l}12(41.4 \%) \\
17(58.6 \%)\end{array}$ & $\begin{array}{c}4(19.4 \%) \\
17(80.09 \%)\end{array}$ & $0.095 \mathrm{NS}^{\mathrm{a}}$ \\
\hline $\begin{array}{c}\text { Co-morbid substance use } \\
\text { Present } \\
\text { Absent }\end{array}$ & $\begin{array}{l}16(55.2 \%) \\
13(44.8 \%)\end{array}$ & $\begin{array}{l}10(47.6 \%) \\
11(52.4 \%)\end{array}$ & $0.598 \mathrm{NS}^{\mathrm{a}}$ \\
\hline $\begin{array}{l}\text { YMRS Scores } \\
(\text { Mean } \pm \text { SD) }\end{array}$ & $41.51 \pm 8.05$ & $36.62 \pm 6.43$ & $0.026^{* b}$ \\
\hline $\begin{array}{l}\text { BPRS scores } \\
(\text { Mean } \pm \mathrm{SD})\end{array}$ & $46.31 \pm 7.20$ & $37.33 \pm 6.35$ & $0.001^{* b}$ \\
\hline $\begin{array}{c}\text { Scores on GAF Scale } \\
11-20 \\
21-30 \\
31-40 \\
41-50\end{array}$ & $\begin{array}{c}4(14 \%) \\
14(49 \%) \\
10(34 \%) \\
1(3 \%)\end{array}$ & $\begin{array}{c}1(4.76 \%) \\
6(28.6 \%) \\
13(61.9 \%) \\
1(4.76 \%)\end{array}$ & $0.239 \mathrm{NS}^{\mathrm{a}}$ \\
\hline
\end{tabular}

Discussion:

(*significant, $\mathrm{p}<0.05),{ }^{\mathrm{a}} \mathrm{Chi}$ square test used, ${ }^{\mathrm{b}}$ independent sample $\mathrm{t}$ test used 
Secondly, patients with mood incongruent psychotic symptoms are often diagnosed as schizophrenia [18] rather than Bipolar I mood disorder and may have got excluded from some of the studies on the subject.

Among the patients with psychotic features, $66 \%$ had mood congruent psychotic features while $34 \%$ had mood incongruent psychotic features. A study [20] had also reported the prevalence of mood incongruent psychosis in mania to be $38 \%$. However, there are vast differences in the rates of mood congruence observed in other studies with a study showing rates as low as $16.5 \%$ [18] and another study showing rates as high as $77.4 \%$ [22].

In this study, all the 29 patients with psychotic features had delusions. None had hallucinations alone. A study done by Black [23] has reported that among psychotic patients, bipolar mania patients were more likely than other diagnostic groups to have delusions only and less likely to have hallucinations only.

In the present study, 14 out of the 29 psychotic patients i.e. $48.3 \%$ had hallucinations along with delusions. These findings are very similar to a study done by Bowman and others [24] which found the prevalence of hallucinations to be $48 \%$ in psychotic manic patients.

Only auditory hallucinations were reported in our study. This finding is in keeping with a study done by Brandon and others [20] which found that auditory hallucinations were the most prevalent in manic states. However, this study also reported a prevalence of $20 \%$ for visual hallucinations. No patient was noted to have visual hallucinations in our study. As the present study had excluded any patient suspected to have an organic etiology, this could have contributed to this finding.

In the present study, grandiose delusions were the most common, followed by those of reference and persecution. Similar findings were reported in a study [20] i.e. grandiose delusions were the most common $(66 \%)$ followed by those of reference $(56 \%)$ and persecution $(31 \%)$, delusions of thought broadcasting $(16 \%)$, Thought control (15\%), somatic (7\%) and bizarre (5\%). A study also observed grandiose delusions to be the most common type of psychotic symptom [5].

In the present study, statistical analysis showed that there was no difference between the two groups on the socio-demographic variables except for socio-economic status. This is in keeping with other studies [25].

A study done by Tohen and others [26] found that although there is good syndromal recovery in affective psychosis, the return to premorbid functional status is poor. These findings suggest that psychotic symptoms in mania carry a grave functional prognosis. This could have contributed to the significantly lower socio-economic status among patients with psychotic features in our study.

There was no significant difference in the age of onset and the occurrence of psychotic features in our study. An Indian study [27] had reported that symptom presentation in youth was similar to the adult onset cases. This is in contrast to a study which found that psychotic manic patients had an earlier age of onset as compared to non psychotic patients [18]. However, younger age of onset has not been associated with psychosis in all studies. Mc Elroy and others [28] found that compared with adults, adolescent patients displayed a significantly lower rate of psychotic features.

One of the reasons for this variation could be a result of difficulty in recall of the patients and their relatives. The present study considered age of onset as the age at which patient first reported being ill or family members first noticed symptoms or impaired functioning. If none could be recalled then patient's first contact with health services was used. Earlier research has shown that a substantial number of years may separate those phases.

In our study, $41 \%$ of the patients with psychotic features had a family history of mental illness as opposed to $19.04 \%$ of patients without psychotic features but this difference was not statistically significant. A study [29] found that psychotic features in mania were unrelated to a family history of mental illness. However, this is in contrast to some of the past research [30] which found that significantly more families of psychotic probands than families of non-psychotic probands (64\% versus $28 \%$ ) contained at least one relative who had affective disorder with psychotic symptoms. Another study [25] found that family history of bipolar disorder was significantly more common in patients with non-psychotic bipolar disorder compared to patients with a history of psychosis.

These differences could probably be explained by the different methodologies used in different studies. In this study, a detailed family history was first taken from the care-givers and confirmed wherever possible with the available past medical records. 
In our study, there was no significant difference in the occurrence of substance use between the two groups. This is in contrast to a study done [18] which reported that psychotic patients used more substances than others.

In this study, patients with psychotic features had significantly higher scores on the YMRS and BPRS as compared to the patients without psychotic features. No such associations were noted with the GAF scores. Past research has also shown that psychotic features had significantly higher BPRS -psychosis subscale scores [20] and significantly higher baseline mania scores [20] and more severe symptom ratings [28], compared with the non psychotic group.

\section{CONCLUSIONS}

The prevalence of psychotic features (delusions and hallucinations) was $58 \%$ in this study. Among the patients who had psychotic features, $51.7 \%$ had only delusions. None of the patients had hallucinations alone. Of the psychotic patients, $48.3 \%$ had both delusions and hallucinations. $66 \%$ of the psychotic patients had mood congruent psychotic features. The rest i.e. $34 \%$ had mood incongruent psychotic features. The most common type of delusions were grandiose delusions that were seen in $54 \%$ of the psychotic patients, followed by delusions of reference and persecution which were seen in $46 \%$ of the patients. Auditory hallucinations were the only type of hallucinations noted. There was no significant difference between the two groups (psychotic versus non-psychotic patients) as regards to sociodemographic variables of age, sex, education, employment and marital status. The patients having psychotic features had significantly lower socio-economic status than the non-psychotic patients. The two groups did not differ significantly as regards to illness related variables age of onset, family history of mental illness or substance use. Patients with psychotic features had significantly higher scores on the Young Mania rating scale (YMRS) and the Brief Psychiatric rating scale (BPRS) as compared to nonpsychotic patients. So such differences were noted as regards to the scores on the GAF scale.

Psychosis is quite common in Bipolar I Mood Disorder in Mania, with approximately half the patients possessing a lifetime history of psychotic symptoms during a manic episode. Our findings suggest that psychotic symptoms are a component of severe manic episodes that, independently of the manic syndrome, contribute substantially to the overall severity of the illness. This implies that rather than independent treatment of mania and psychosis, vigorous treatment of underlying mania may, at least in some patients, bring about a resolution of psychosis.

\section{REFERENCES}

1. Gitilin MJ, Swendsen J, Heller TL, Hammen C. Relapse and impairment in bipolar disorder. Am J. Psychiatry 1995;152:1635-40.

2. Altshuler LL, Gitlin MJ, Mintz J, Leight KL, Frye MA. Sub syndromal depression is associated with functional impairment in patients with Bipolar Disorder. J. Clin Psychiatry 2002;63:807-11.

3. Harrow M, Goldgerg JF, Grossman LS, Meltzer HY. Outcome in manic disorders.A naturalistic follow up study. Arch Gen Psychiatry 1990;47:665-71.

4. Goodwin FK, Jamison KR. Manic Depressive Illness. New York: Oxford University Press. 1990.

5. Dunayevich E, Keck PE Jr: Prevalence and Description of Psychotic features in Bipolar mania. Curr Psychiatry Rep 2000;2(4):286-90.

6. Pope HG, Lipinski JF. Diagnosis in schizophrenia and Manic Depressive illness: A reassessment of the specificity of "schizophrenic" symptoms in the light of current research. Arch Gen Psychiatry 1978;35:81128.

7. Rosen LN, Rosenthal NE, DunnerDL, Fieve RR. Social outcome compared in psychotic and non psychotic Bipolar I patients. J Nerv Ment Dis 1983;171:272-5.

8. Tohen M,Waternaux CM, Tsuang MT. A four year prospective follow up of 75 patients utilizing survival analysis. Arch Gen Psychiatry 1990;47:1106-11.

9. Goldgerg JF, Harrow M, Grossman LS.Course and Outcome in Bipolar Affective Disorder: A longitudinal follow up study. Am J Psychiatry 1995;152:379-84. 
10. Judd LL, Akiskal HS, Schettler PJ, EndicottJ, Maser j, Solomon DA, Leon AC, Rice JA, Keller MB. The long term natural history of the weekly symptomatic status of Bipolar I disorder. Arch Gen Psychiatry 2002;59:530-7.

11. Coryell W, Leon A, Winokur G, Endicott J, Keller M, Akiskal HS, Solomon D. Importance of psychotic features to long term course in major depressive disorder. Am J Psychiatry 1996;153:483-9.

12. Guadiano BA, Beevers CG, Miller JW. Differential response to combined treatment in patients with psychotic versus non psychotic major depression. J Nerv Ment Dis 2005;193:625-8.

13. American Psychiatric Association. DSM IV TR. Diagnostic and Statistical Manual of Mental Disorders.Fourth Edition.Text Revision. Washington D.C. USA ; 2000.

14. Kuppuswamy B. Manual of socio-economic status scale (Urban). Manasayan. New Delhi ; 2001.

15. Endicott J, Spitzer RL, Fleiss JL, Cohen J: The Global Assessment scale. A procedure for measuring overall severity of Psychiatric Disturbance. Arch Gen Psychiatry 1976;33:766-71.

16. Young RC, Biggs JT, Ziegler VE. A rating scale for mania. Reliability, validity and sensitivity. Br J Psychiatry 1978 133:429-35.

17. Overall JE and Gorhom DR. The Brief Psychiatric Rating Scale. Psychol Rep 1962;10:799-812.

18. Azorin JM, Akiskal H, Hantouchec E. The mood instability hypothesis in the origin of mood-congruent versus mood incongruent psychotic distinction in mania: validation in a French National study of 1090 patients. J Affect Disord 2006;96:215-23.

19. Black DW, Winokur G, Nasrallah A, Brewin A. Psychotic symptoms and age of onset in Affective Disorders. Psychopathology 1992;25:19-22.

20. Brandon A, Guadiano BA, Lisa A. Uebelacker and Ivan W. Miller. Course of illness in psychotic mania. Is mood incongruence important? J Nerv Ment Dis 2007;195:226-32.

21. Haro JM, Van Os J, Vieta E, Reed C, Lorenzo M, Goetz I. EMBLEM advisory board. Evidence for three distinct claases of "typical" "psychotic" and "dual"mania: Results from the EMBLEM study. Acta Psychiatr Scand 2006; 113(2):112-20.

22. Fenning S, Fenning - Naisberg S, Karant M. Mood congruent versus mood incongruent psychotic symptoms in affective psychotic disorders. Isr J Psychiatry Relat Sci 1996;33(4):238-45.

23. Black DW, Nasrallah A. Hallucinations and Delusions in 1715 patients with unipolar and bipolar affective disorders. Psychopathology 1989;22:28-34.

24. Bowman KM, Raymond AF. A statistical study of hallucinations in the manic-depressive psychoses. Am J Psychiatry 1931;88:299-309.

25. Keck PE JR, Mc Elroy SL, Rochussen Havens J, Altshuller LL. Psychosis in bipolar disorder: Phenomenology and impact on morbidity and course of illness. Compr Psychiatry 2003;44:263-9.

26. Tohen M, Hennen J, Zarate Jr CM, Baldessarini RJ, Strakowski SM, Stoll AL, Faedda GL, Suppes T, Gebre-Medhin P, Cohen BM. Two-year syndromal and functional recovery in 219 cases of first-episode major affective disorder with psychotic features. Am J Psychiatry 2000;157:220-8.

27. Janardhan Reddy YC, Girimaji S, Srinath S. Clinical profile of mania in children and adolescents from the Indian subcontinent. Can J Psychiatry 1997;42:841-6.

28. McElroy SL, Strakowski SM, West SA, Keck Jr PE, McConville BJ. Phenomenology of adolescent and adult mania in hospitalized patients with bipolar disorder. Am J Psychiatry 1997;154(1):44-9.

29. Coryell W, Leon AC, Turvey C, Akiskal HS, Meuller T, Endicott J. The significance of psychotic features in manic episodes: a report from the NIMH collaborative study. J Affect Disord 2001;67(1-3):79-88.

30. Potash JB, Willour VL, Chiu YF, Simpson SG, MacKinnon DF, Pearlson GD, DePaulo Jr JR, McInnis MG. The familial aggregation of psychotic symptoms in bipolar disorder pedigrees. Am J Psychiatry 2001;58:1258-64.

Acknowledgements - We would like to thank the Dean, K.J. Somaiya Hospital and Research Centre, Mumbai, India for his help and cooperation. We would also like to thank our patients and their care-givers for their co-operation.

Source of Funding - Nil

Conflict of Interest - Nil 